$\xi=-1$

\title{
Innovations and recent trends in Shape Memory Alloy: a review
}

\author{
Saurabh. S. Kawate ${ }^{1}$, Chethan. K. N ${ }^{2}$, Laxmikant G Keni ${ }^{2}$, Anand Pai ${ }^{2}$, Padmaraj. N. H ${ }^{2 *}$ \\ ${ }^{I}$ P. G Student, Department of Aeronautical and Automobile Engineering, Manipal Institute of Technology, Manipal Academy of Higher \\ Education, Manipal, 576104, India \\ ${ }^{2}$ Assistant Professor-Senior Scale, Department of Aeronautical and Automobile Engineering, Manipal Institute of Technology, Manipal \\ Academy of Higher Education, Manipal, 576104, India \\ *Corresponding author E-mail: padmaraj.nh@manipal.edu
}

\begin{abstract}
Smart materials are materials, which have a definite response to stimulus provided through a change in pressure, temperature and termed as shape memory alloys (SMA). In this review, the general concept of SMA's has been discussed along with shape memory effects. Shape memory material properties depend on phase shifting phenomena, which consist of pseudoelasticity and thermoelasticity. The basic SMA such as Ni-Ti (Nickel-Titanium) alloys, Copper $(\mathrm{Cu})$ based SMA, Iron (Fe) based SMA are commonly used in the industry, $\mathrm{Ni}-\mathrm{Ti}$ alloys are expensive but it has good super elasticity and superior mechanical properties. $\mathrm{Cu}$ and $\mathrm{Fe}$ based are economical as compared to the Ni-Ti alloys. The various fabrication techniques and common composition of the alloys have been discussed with in detail.
\end{abstract}

Keywords: Shape Memory alloy; Nickel-Titanium.; Fabrication Techniques of SMA; Actuators; Nitinol.

\section{Introduction}

With evolution of technology, smart materials play a vital role in replacing the conventional materials. Smart materials are the materials that are responsive to stimuli such as the temperature, pressure, electric flow and magnetic flux. These materials are also known as the SMA's. SMA are the materials, which remembers the original shape of the material, and it can regain its shape when it is subjected to heat, magnetic variation and cryogenic conditions. SMA are of various types such as high temperature SMA, magnetic SMA, shape memory thin film, shape memory polymers and many more[1][2]. The SMA properties depend on the phase shifting phenomena. It mainly takes place in two phases- firstly in the martensite phase and secondly in the austenite phase. The martensite phase is called as the cold phase, while the austenite phase is called as hot phase. The characteristics of the shape memory effect is pseudoelasticity and thermoelasticity. These properties tend to bring the material back to the original shape after the load is removed. This effect is also known as super elastic effect. The shape memory effect is further classified into two types- one-way shape memory effect and two-way shape memory effect[3]. The temperature phases associated in the SMA are austenite finish $\left(\mathrm{A}_{\mathrm{f}}\right)$ where the original shape is recovered, second is the austenite start $\left(A_{s}\right)$ where the recovery is started, third is the martensite start $\left(\mathrm{M}_{\mathrm{s}}\right)$ and martensite finish $\left(\mathrm{M}_{\mathrm{f}}\right)$ where the martensite transformation starts and finishes[4]. One-way shape memory effect is the effect in which only the parent shape is recovered, while in two-way shape memory effect both the parent and product phase is memorized [5]. The commonly used SMA is Gold based SMA, Ni-Ti (Nitinol), Copper based SMA and Iron based SMA. Out of all of these, Ni-Ti alloys are the most effective due to their superior physical and mechanical properties. Ni-Ti alloys are expensive, hence researcher are trying to make different types of SMA's that are economical and have more physical properties as compared Ni-Ti.[6]. Gold based was the first identified shape memory material. It is mainly used in the jewelry industry and is expensive because of gold usage. Copper and iron based SMA's are cheaper than Gold based and they can be used in various applications where temperature is taken into account. It is mainly alloyed with aluminum where $\mathrm{Cu}-\mathrm{Zn}-\mathrm{Al}$ and $\mathrm{Cu}-\mathrm{Al}-\mathrm{Ni}$ are the composition [7] [8]. There are some ferromagnetic materials that are used in industry [9]. The ferromagnetic can work as a SMA. It can be used for the applications where the length can be changed by converting the magnetic signal to mechanical power useful in application of actuators. The ferromagnetic materials are used to make a SMA's by the combination of Ni-Mn-Ga (Gallium) which are compatible at room temperature [10] [11]. SMA's have good properties for seismic applications hence it can be used in civil applications such as concrete beam, smart structures and many more [12].

\section{Various types of SMA's}

\subsection{Nitinol}

William Buehler an American supervisor working in the U.S. Navy discovered an alloy of Nickel and Titanium, which are mainly mixed with the composition of Ni-45\% Ti-55\%, Ni-55\% Ti-45\%, Ni-50\% Ti-50\%. The word Nitinol is introduced from the laboratory name and are commonly named as Ni-Ti alloys. The transformation temperature of Ni-Ti alloys is between 0 to $100{ }^{\circ} \mathrm{C}$ [13]. The commonly accepted Ni-Ti alloy for various application is of the composition of $\mathrm{Ni}(50.8 \%$ by atomic weight) and remaining $\mathrm{Ti}$. Increasing or decreasing the composition of $\mathrm{Ni}$ and $\mathrm{Ti}$, phase transformation temperature can be modified [14]. In 1920, the Ni-Ti alloys were used in industry to couple two pipes. The coupling was made of SMA and it was smaller in diameter than that of the regular pipes [15]. When the coupling was inserted between two pipes and heated, it attained its original shape and on cooling, achieved proper coupling of the pipes [16] [17]. It offered 
additional advantages such as wear resistance, biocompatibility, high strength, less weight. Applications of Ni-Ti SMA's were extended to medical applications such as implants, orthodontic wires, angioscopy [18]. Chromium (Cr), $\mathrm{Cu}$ alloys can be mixed with $\mathrm{Ni}-\mathrm{Ti}$ to improve the SMA properties [19]. Ni-Ti-Cu alloys show good linear relationship between electrical resistance and deformation [20]. Among Ni-Ti-Cu alloys, the Ti- rich alloys exhibited compound twinning effect on annealing with improved elasticity. The higher content of $\mathrm{Ti}$ in the composition affects the formation of martensite variants which decreases the transformation stresses during thermomechanical cycling[4]. Ti-Ni alloys are extremely expensive which provided an impetus to study alternate SMA's [1] [9] [21]. The limitation of the Ni-Ti alloys in the medical applications is that it releases toxic elements within tissues and cannot be detected through X-ray analysis. This can be eliminated by incorporating Tantalum (Ta) along with the basic $\mathrm{Ni}-\mathrm{Ti}$ alloy. Fabrication creates a layer of Ti-Ta layer on the surface of the composition(Ti70\%-Ta30\%) [22]. The temperature range is also increased to $400^{\circ} \mathrm{C}$, that increases cold workability properties and makes the SMA malleable and ductile [23]. Corrosion of Ni-Ti was observed in human cells due to release of Nickel. Corrosion resistance of Ni-Ti alloy improved by coating with Ta and annealing between $700-900^{\circ} \mathrm{C}$ for an hour [24] [25] [26] The super elastic property can be obtained by proper thermomechanical treatment. The ductility of Ni-Ti alloy is quite good than that of beta phase SMA. The beta phase transformation temperature changes during the martensite phase. In Ni-Ti alloys, this effect is not observed, because the melting temperature are high with limited diffusion phenomena. Ni-Ti alloys have good damping properties [27]. The spectrum intensity of $\mathrm{Ni}$ can be affected by the sputtering pressure, but it does not affect $\mathrm{Ti}$ and $\mathrm{Cu}$ [28]

\subsection{Copper based SMA}

Copper based SMA's were discovered in early 1950's as a substitution to gold based SMA with enhanced manufacturability and mechanical response, at the same time being economical. $\mathrm{Cu}-\mathrm{Al}$ is the most common combination, but the transformation temperature range is too high for applications, hence third material is added to the composition to overcome this problem. $\mathrm{Cu}-\mathrm{Zn}-\mathrm{Al}, \mathrm{Cu}-$ $\mathrm{Al}-\mathrm{Ni}, \mathrm{Cu}-\mathrm{Al}-\mathrm{Mn}, \mathrm{Cu}-\mathrm{Al}-\mathrm{Be}$ are the most commonly used copper based SMA [29]. Zinc and Nickel SMA's are commonly used owing to good availability and economic nature[30]. The recovery strain in these alloys is up to $5 \%$ with good cold workability. $\mathrm{Zi}$ Ni SMA's undergo two-way shape memory effect. $\mathrm{Cu}-\mathrm{Al}-\mathrm{Ni}$ alloys were considered as High Temperature SMA's [31]. The strength of the $\mathrm{Cu}-\mathrm{Al}-\mathrm{Ni}$ increases with annealing time [32]. When $\mathrm{Cu}-\mathrm{Al}-\mathrm{Mn}$ is manufactured using laser welding techniques it was found that the tensile strength and the strain recovery percentage increased up to $1.7 \%$, with increase in damping property[33] [34]. $\mathrm{Cu}-\mathrm{Al}-\mathrm{Mn}$ SMA's have more ductility than that of $\mathrm{Cu}-\mathrm{Zn}-\mathrm{Al}$ along with corrosion resistance. By addition of different additives such as $\mathrm{Zn}, \mathrm{Si}, \mathrm{Fe}, \mathrm{Cr}$ to $\mathrm{Cu}-\mathrm{Al}-\mathrm{Mn}$ SMA; the shape memory effect can be improved. By addition of $\mathrm{Mg}$, phase transformation temperature improves [35] [36]. Cu-Al-Mn-Ni SMA's are super elastic alloys with the high elasticity modulus obtained through compression testing [37]. Annealing of $\mathrm{Cu}-\mathrm{Al}-\mathrm{Mn}-\mathrm{Ni}$ alloys will decrease the stored elastic energy; will accelerate the austenite start phase as compared to austenite finish phase. Latent heat of transformation, elastic energy stored, and the dissipative energy are responsible for the effect of stabilization. The dissipative energy during the transformation makes it easier for martensite transformation [38]. Adding $0.7 \% \mathrm{Ti}$ by mass to $\mathrm{Cu}-\mathrm{Al}-\mathrm{Ni}$ SMA's, corrosion resistance and strain recovery were improved. On corrosion testing, Cu-Al-Mn-Ni SMA's showed pitting corrosion and $\mathrm{Cu}-\mathrm{Al}-\mathrm{Ti}-\mathrm{Ni}$ SMA's showed localized corrosion, but extent of corrosion was less as compared to $\mathrm{Cu}-\mathrm{Ni}-\mathrm{Al}$ alloy [39]. Super elasticity was included in $\mathrm{Cu}-13 \mathrm{Al}-11(\mathrm{Mn}$ and $\mathrm{V})$ alloys on increasing Vanadium (V) composition. Super elasticity was found to be maximum at $\mathrm{V}=1.8$ to $2.1 \%$ weight. The shape memory effect and strain rate increase when $\mathrm{V}$ was increased between 4 to $4.5 \%$ by weight [40].

\subsection{Iron-based SMA}

Iron based SMA's were discovered as an alternative to the Ni-Ti SMA and $\mathrm{Cu}$ based SMA due to lower cost and better properties. It was introduced in Japan as Fe-Mn-Si SMA's. Cr, Ni, Co can be added to the composition that will increase the corrosion resistance [41]. Fe-Mn-Si SMA's can be used for strengthening the concrete beam in civil engineering applications, because Fe based SMA are cheaper than normal Ni-Ti SMA's [42]. The shape memory effect in these materials is very less up to $4 \%$ and fabrication setup is similar to that of a stainless-steel manufacturing. Fe$\mathrm{Mn}-\mathrm{Si}-\mathrm{Cr}$ alloys are used in many applications. The study of super elasticity of Fe-Al-Mn-Ni alloys showed that the heat treatment led to increase in critical strength, while the transformation stresses were increased up to $500 \mathrm{MPa}[43]$. They are mainly used in the applications such as rail joints plates, large-sized pipelines for tunnels [44] [45]. Body centered cubic (BCC) and Face centered cubic (FCC) transformation was analyzed in the new Fe-Mn-Al-Ni SMA for double shear. Face centered cubic martensite formation stresses including the transformation stresses and elastic behavior at the dislocations were studied and the transformation stresses $\sim 191 \mathrm{MPa}$ found to be in good agreement with the experimental values[46].

\section{Fabrication of SMA's}

Variation in shape memory effect can be achieved by fabricating thin sheet of the materials. The fabrication technique consists of various types of powder metallurgy technique, such as solid-state sintering, hot extrusion, hot pressing, metal injection molding, mechanical alloying and many more. But these processes have limitations such as formation of stable secondary phase after the elongation of the wire [14]. Laser based additive manufacturing process is one of the widely used process for fabrication which was compared for $\mathrm{Ni}-\mathrm{Ti}$ alloys of different composition such as $\mathrm{Ni}-45 \% \mathrm{Ti}-55 \%$, Ni-55\% Ti-45\%, Ni-50\% Ti-50\%. The samples were further tested in X-ray diffraction machine(XRD) and hardness testing machine [47]. Results showed that the ductility of the material increases and porosity of the material decreases, while this technique can be used for manufacturing alloys of $\mathrm{Cu}-\mathrm{Cr}$ alloys [14] [48]. Infrared brazing of $\mathrm{Ni}-\mathrm{Ti}$ with $\mathrm{Cu}-\mathrm{Ag}$-Ti using active brazing alloy was analyzed. The shear strength increases on brazing with improved wettability [49]. Shape memory effect of laser welding on $\mathrm{Ni}-\mathrm{Ti}$ plates were carried out and subjected to bending, microstructure analysis and X-ray diffraction. From the results, complete shape memory effect was observed and perfect phase transformation took place upto $100 \%$ in the bending test through $180^{\circ}$ In-plane [50] [51] [52]. Copper based SMA's are less expensive than that of Ni-Ti alloys, but they do not possess the physical properties of Ni-Ti. To improve the properties, the $\mathrm{Cu}$ based materials were welded using laser welding technique. Experiment was done for observing the thermomechanical fatigue of post-weld NiTi SMA. YAG pulsed laser welding process was used for fabrication process [6]. It was observed that $86 \%$ of the tensile strength was maintained, but the actuation stability and cycle life was decreased. On heat treatment, the stability and cycle life of the wire were improved. Manganese and aluminum bronze composite SMA were manufactured by roll bonding process. The manganese-based SMA's increase the ductility as compared to the $\mathrm{Cu}-\mathrm{Zn}-\mathrm{Al}$ alloys. They are based on thermos-elastic transformation that takes place in the beta phase. The composites are produced by copper and aluminum strips and manganese powder and are bonded by rolling operation such as accumulative roll bonding process and heat treated till it reached the required microstructure (Composition of $\mathrm{Cu} 83 \% \mathrm{Al} 12 \%$ and $\mathrm{Mn} 5 \%$ ). Annealing process is done at temperature of $950^{\circ} \mathrm{C}$ and the specimen was evaluated under energy dispersive $\mathrm{X}$-ray spectroscopy. Phase transformation 
and the microstructure depend on the temperature and the corrosion resistance increases due to the presence of bronze [30]. Powder metallurgical method is used for fabrication of Ni-Ti-Nb (Niobium) and Ni-Ti-Cu SMA using pre-alloyed powders [53] [54]. It was observed that by introducing $\mathrm{Nb}$ in $\mathrm{Ni}-\mathrm{Ti}$ alloys, the castability improved. $\mathrm{Cu}$ addition was found to increase the pore size and porosity [49] [52] [53]. To increase the radio-capacity of medical devices such as filters and stents, the gold plating on Nitinol alloys was useful. Wet-to-wet electroplating to a deposition thickness $\sim 4 \mu \mathrm{m}$ does gold plating. The deposition thickness higher than $4 \mu \mathrm{m}$ affects the elasticity of the material. Hydrogen amount should be controlled to avoid Ni-Ti embrittlement [55]. Plasma immersing ion implantation deposition technique (PIIID) was used to fabricate $\mathrm{Ni}-\mathrm{Ti}$ alloys with tantalum for increasing corrosion resistance. PIIID technique combines the advantages of plasma immersion ion implantation and magnetron deposition methods [56].Machining of SMA's is a huge challenge for ensuring high quality of materials and minimizing wear-and-tear of tool materials. Hence, non-conventional techniques like the water jet machining (WJM), electrochemical machining (ECM), Electrical discharge machining (EDM) and wire EDM (WEDM) are employed. These methods have the ability of manufacture any material to required shape. The materials removal rate of the EDM and the WEDM is more as compared to the commonly used traditional methods with significant reduction in the cycle time. The process can be enhanced further by adjusting the voltage, reducing the diameter of wire and speed optimizing the speed. By optimizing the above parameters the output will be more precise and best for usage [57].

\section{Applications of SMA}

SMA's have a great importance in the aerodynamics applications The use of SMA will decrease the weight of the of the air craft, so the fuel consumption of the air craft is minimized. Eventually it will decrease the overall operational cost of the air craft. The use of SMA in the aerospace is to reduce the low shock release. Another application included SMA-actuated solar collectors utilizing the torsional element which can change the shape and increase the efficiency. SMA are also used as the sensing device as they are used to receive the information for the subsystem by using the change of the thermal property. As SMA exhibit pseudo-elasticy, it reduces the vibration isolation and large recoverable deformation [58] [8]. For micro-sized mechanical components, SMA's show several advantages like simplicity in construction, cleanliness, silent operation, less space requirement. Hence these components can be manufactured by using SMA's [59]. The lifting surface of the airplane is range-dependent with varying performance of the plane because of the lack of structural rigidity at high-speed conditions. To overcome this, SMA's can be used for morphing aircrafts. SMA's can be used to lift the pilot surface to the required position according to the conditions and to reduce the aerodynamic load by deformation of the smart material according to the operating condition. It is mostly suitable for rotary wing aircraft of various sizes. To maintain the system, benefit the morphing technique should use less amount of power and this can be achieved by modifying the smart materials than the normal ones [60]. For overcoming these disadvantages, the SMA used in the aircraft must be standardized with adequate mechanical characterization in terms of tensile, compression and thermal. The hybrid model describes the relationship between the temperature, change in length and the internal forces in the SMA spring actuator [61]. The various SMA's should be standardized. The test involves tension, compression, recovery and thermal cycling tests [58]. The goal of the actuator used in the helicopter rotor is to decrease vibration for every degree of revolution arising out of dissimilarities in the rotor. The objective of the rotor was to achieve the deflection of about $\pm 5^{\circ}$ with an accuracy with $0.1^{\circ}$. The actuation is depending on bidirectional motion of a pairs of SMA with friction brakes to lock the tab position. Modelling and testing were carried out different external loading condition [62]. SMA's can be also used in heat engines. The SMA wire is coiled over the heat engine and air is passed through it. The material of the coil used in this process is Ni-Ti SMA. The engine generates the mechanical power from it by expanding the wire according to hot or cold air using the SMA transformation [63] [64]. Heat recoverable coupling technique used in shipyard production. SMA like Nitinol was used for coupling of two pipes in the field of ship yard production [65]. In modern cars, the SMA actuators can be used for controlling of engine, suspension system, transmission, improving safety and comfort for the passenger. Ni-Ti SMA are universally used in automotive applications [66]. Another SMA application in automobile field is mirror actuator; the SMA wires are used to position the mirrors externally. They are also called as second-generation actuators. The rotation takes place in both the $x$ and z-axes [67]. SMA resettable springs have been developed for pedestrian protection from impending collision with the automobile. The lift is possible by spring, which is made by SMA. Use of SMA makes the setup light in weight and compact which is also possible because of solenoid and electrical motors [68] [69]. The use of SMA for miniature actuator using the base of mechatronics has been explored. Automobile tumble flap made from SMA are replaced by the flaps working on electromagnetic and pneumatic effectors, which was traditionally used for operation of tumble for intake manifold in the engine [70]. The actuators used in automobile are made of SMA that require input energy for operation. The power required can be used from the battery of the vehicle [71]. SMA actuator can be used for startup of clutch as clutch requires high torque [72]. SMA's can be used for the application of morphing the axial fan blade used in engine. The cooling system of the automobile is controlled by using sensors and cooling system that increases the number of sensors and makes the system heavy. Axial fan based on morphing blades can be made of SMA that changes the shape when the temperature of the air increases passing from the fan and brings it to the memorized shape. The deflection of the blade is more as compare to the glass fiber on thermal activation. By using these types of blades, there will be elimination of sensors and electric motors that saves cost. The load on battery can be decreased improving battery life [73]. With the use of micro-electronics, there is need of cooling at micro and Nano scales. Electro-caloric cooling can be used as an alternative for thermos-electrical types, due to large latent heat and good down scaling behavior [13]. The unmanned water vehicle is used to maintain the buoyancy during various temperature ranges. The smart materials can be used for maintaining the buoyancy. It can be used under two working conditions, firstly, at low temperature, the wire length increases, applying tension on the cylinder which increases the buoyancy. When the temperature decreases, the wire compresses and the spring expands which decreases the area of the cylinder eventually decreases the buoyancy. This smart material can be used in commercial waterways applications and also in naval operations [74]. SMA's can be used in soft actuating materials for the applications of the robotic gripper. The soft smart composites are used for pure maximum bending in some sections. The maximum bending of the wire can be achieved [75]. SMA actuators use internal electric resistance feedback. There are two types of SMA's actuators- position sensor and position-feedback sensor for greater accuracy [76]. Morphing hand using a SMA wire is another application used in robotic manipulator. Artificial hand or the robotic manipulator are made with various joints and motors, but they need feedback system that makes the system bulky and expensive. By using SMA's, morphing hand can be made that can perform their operation without any feedback system. The wire is mainly composite of soft materials and the SMA's. The soft materials are used for the wires since they are flexible in nature and the SMA's will perform the bending and contraction of the wire as per requirement. The stiffness can be increased by increasing the number of glass fiber sheets [77]. Fe-Mn-Si SMA's can be used for strengthening the concrete beam in civil engineering applications since they are less expensive than Ni-Ti SMA's. Near surface mount technique can be used using SMA's that will reduce 
the probability of harm during fire, corrosion damage or mechanical damage. Test were carried on a reinforced concrete beam to check the flexural behavior and Fe based SMA's were prestressed. Pre-stressing increased the strength of the beam, it also reduces stresses in steel and increases fatigue resistances and reduce the crack width in beam. Pre-stressing in this application is it easy as doesn't require mechanical components such as jacks and anchor heads, which is also one of the important advantage [42]. Smart structures are also used in civil engineering field. There are two types- active and semi-active control systems. Active structure consists of active tune mass damper, while semi active control system are Magnetorheological (MR) fluid dampers [78]. Ni-Ti alloys is a SMA that can be used in the biomedical applications due to biocompatibility [1]. As this material have two-way shape memory effect, hence it can be used in the applications of implants of the bones. Interventional radiology is the main application in which Nitinol wire is used for performing angiography through wire-insertion [17] [79]. Ni-Ti SMA's are also used in orthodontic applications. Wires get subject to mechanical stresses and reaction with acids, mainly the fluoride present in the foods. The super elastic behavior can be used for loading and unloading the teeth. Properties of this alloys are very favorable for using in the endodontology for construction of root canal when applying curvy canal [80]. Corrosion does not occurs in the wire hence it can be used in the medical application [16] [21]. Ni-Ti SMA's can be used in laparoscopic surgery where an endoscopic camera can be inserted in the body to view in various directions. Endoscopic grasper to remove stone in the bladder was made from Ni-Ti SMA's [81]. A smart material can be used for 3D printing, as smart materials changes shapes when load is applied, or when temperature is varied and in turn, it gives rise to a new concept of 4D printing. Material used for 4D printing may be single material or multiple materials. Single material depends on the smartness of the material and the component reacts on actuation. In case of multi-materials, it depends on the complexity of integral design of material and also depends on properties of individual materials such as compression, tension [82]. SMA's for moving flap of air conditioner, the temperature-sensing element was developed by Matsushita Electric. The use of SMA's developed in appliances like coffee maker, electric rice cooker and many more day to day appliances were commercialized. SMA's wires are also used in telecommunications like antenna of telephone using the principle of super elasticity. [83]. It can be used for making curtains mechanism that uses nitinol wire in the curtains that expands when the temperature increases by the effect of the sun causing the curtains to close. The curtains opens when the temperature during the day decrease to a preset value. The temperature of this wire is set to $25^{\circ} \mathrm{C}$. It may be used for making the table lamp with nitinol coil in it, when the temperature increases; it disturbs the circuit and closes the lamp. By reusing this material and applying in day to day applications we can eventually decrease pollution and it will be an eco-friendly way of material [84].

\section{Conclusion}

Study of SMA's such as its phase transformation has been discussed in detail. The shape memory effect consists of two phasesfirst is the martensite state and the austenite state. The austenite state occurs mainly at high temperature while the martensite state occurs at low temperature or room temperature. Ni-Ti alloy is most commonly used due to its good properties, bio-compatibility and many more. The shape memory effect of this alloy is upto $10 \%$ at temperature range of 0 to $100^{\circ} \mathrm{C}$. Hence, development of other alloys like copper-based alloys were undertaken. $\mathrm{Cu}$ are mainly alloyed with aluminum and by mixing zinc and nickel, SMA properties are enhanced. The most commonly used copperbased SMA's are of $\mathrm{Cu}-\mathrm{Zn}-\mathrm{Al}, \mathrm{Cu}-\mathrm{Ni}-\mathrm{Al}$. As copper is used this type of SMA's these are used in security application, thermal applications. Iron based SMA's were introduced with compositions like $\mathrm{Fe}-\mathrm{Mn}-\mathrm{Si}$, while $\mathrm{Cr}$, Co enhance the corrosion resistance. The shape memory effect of this alloy is up to $4 \%$ and it generally occurs at elevated temperature. Various application is discussed which includes both technical and medical applications.

\section{References}

[1] J. Mohd, M. Leary, A. Subic, and M. A. Gibson, "A review of SMA research, applications and opportunities," Mater. Des. vol. 56 , pp. 1078-1113, 2014. https://doi.org/10.1016/j.matdes.2013.11.084.

[2] P. P. A. A, M. K. D, and M. P. P. Jivrag, "Smart Materials," vol. 13 no. 5, pp. 28-32, 2016.

[3] L. Sun and W. M. Huang, "NATURE OF THE MULTISTAGE TRANSFORMATION IN SMA'S UPON HEATING," vol. 51, 2009.

[4] X. L. Meng, M. Sato, and A. Ishida, "Structure of martensite in Tirich $\mathrm{Ti}-\mathrm{Ni}-\mathrm{Cu}$ thin films annealed at different temperatures," vol 56, pp. 3394-3402, 2008

[5] N. Gabdullin, S. H. Khan, A. A. Rogovoy, and O. S. Stolbova, "SMA's : a state of art review."

[6] B. Panton, J. P. Oliveira, Z. Zeng, Y. N. Zhou, and M. I. Khan, "Thermomechanical fatigue of post-weld heat treated NiTi SMA wires," Int. J. 2016 https://doi.org/10.1016/j.ijfatigue.2016.06.012.

[7] J. P. Oliveira, Z. Zeng, T. Omori, N. Zhou, R. M. Miranda, and F. M. B. Fernandes, "Improvement of damping properties in laser processed superelastic Cu-Al-Mn SMA's," JMADE, vol. 98, pp. 280 284, 2016. https://doi.org/10.1016/j.matdes.2016.03.032.

[8] J. Ma, H. Huang, and J. Huang, "Characteristics Analysis and Testing of SMA Spring Actuator," vol. 2013, no. 1, 2013.

[9] K. K. Alaneme and E. A. Okotete, "Engineering Science and Technology, an International Journal Reconciling viability and costeffective SMA options - A review of copper and iron based shape memory metallic systems," Eng. Sci. Technol. an Int. J., 2016.

[10] E. Faran and D. Shilo, "Ferromagnetic SMA's - Challenges, Applications, and Experimental Characterization," pp. 1-27, 2015.

[11] B. Mohammad, I. Khan, A. Pequegnat, and Y. N. Zhou, "Multiple Memory SMA's **," no. 5, pp. 386-393, 2013

[12] P. Silva, "SMA's behaviour: A review," vol. 114, pp. 776-783, 2015.

[13] H. Ossmer, C. Chluba, E. Quandt, M. Kohl, H. Ossmer, C. Chluba E. Quandt, and M. Kohl, "TiNi-based films for elastocaloric microcooling — Fatigue life and device performance TiNi-based films for elastocaloric microcooling — Fatigue life and device performance," vol. 64102, 2016.

[14] S. Shiva, I. A. Palani, S. K. Mishra, C. P. Paul, and L. M. Kukreja, "Optics \& Laser Technology Investigations on the in fl uence of composition in the development of $\mathrm{Ni}$ - Ti SMA using laser based additive manufacturing," Opt. Laser Technol., vol. 69, pp. 44-51, 2015. https://doi.org/10.1016/j.optlastec.2014.12.014.

[15] A. Vitiello, G. Giorleo, and R. E. Morace, "Analysis of thermomechanical behaviour of Nitinol wires with high strain rates," vol. 215 2005

[16] C. Zhang, S. Zhao, X. Sun, D. Sun, and X. Sun, "Corrosion of laser-welded NiTi SMA and stainless steel composite wires with a copper interlayer upon exposure to fluoride and mechanical stress,' Corros. Sci. vol. 82, pp. 404-409, 2014 https://doi.org/10.1016/j.corsci.2014.01.040.

[17] J. Ma, F. Yang, J. I. Subirana, Z. J. Pu, and K. H. Wu, "Study of NiTi-Ta SMA's," vol. 3324, no. March 1998, pp. 50-57.

[18] M. H. Elahinia, M. Hashemi, and M. Tabesh, "Progress in Materials Science Manufacturing and processing of NiTi implants: A review," Prog. Mater. Sci., vol. 57, no. 5, pp. 911-946, 2012 https://doi.org/10.1016/j.pmatsci.2011.11.001.

[19] J. Frenzel, A. Wieczorek, I. Opahle, B. Maßß, R. Drautz, and G. Eggeler, "ScienceDirect On the effect of alloy composition on martensite start temperatures and latent heats in Ni - Ti-based SMA's," Acta Mater., vol. 90, pp. 213-231, 2015. https://doi.org/10.1016/j.actamat.2015.02.029.

[20] F. Gariboldi, S. Besseghini, and G. Airoldi, "Stress-assisted twoway memory effect electrically driven in 50 at. $\% \mathrm{Ti}-45$ at. $\% \mathrm{Ni}$ -5 at. \% Cu alloy," vol. 440, pp. 653-656, 2006.

[21] W. E. Letaief, T. Hassine, F. Gamaoun, and W. E. Letaief, "Tensile behaviour of superelastic NiTi alloys charged with hydrogen under applied strain Tensile behaviour of superelastic NiTi alloys charged with hydrogen under applied strain," Mater. Sci. Technol., vol. 0, no. 0, pp. 1-6, 2017

[22] L. L. Meisner, A. B. Markov, V. P. Rotshtein, G. E. Ozur, S. N. Meisner, E. V Yakovlev, V. O. Semin, Y. P. Mironov, T. M. Poletika, S. L. Girsova, and D. A. Shepel, "Microstructural characteriza- 
tion of Ti-Ta-based surface alloy fabricated on TiNi SMA by additive pulsed electron-beam melting of film/substrate system," $J$. Alloys Compd., 2017.

[23] P. John, S. Buenconsejo, H. Young, H. Hosoda, and S. Miyazaki "Shape memory behavior of $\mathrm{Ti}-\mathrm{Ta}$ and its potential as a hightemperature SMA," Acta Mater., vol. 57, no. 4, pp. 1068-1077, 2009. https://doi.org/10.1016/j.actamat.2008.10.041.

[24] Y. Cheng, W. Cai, H. T. Li, Y. F. Zheng, and L. C. Zhao, "Surface characteristics and corrosion resistance properties of TiNi SMA coated with Ta," vol. 186, pp. 346-352, 2004

[25] G. Xu, X. Shen, Y. Hu, P. Ma, and K. Cai, "Surface \& Coatings Technology Fabrication of tantalum oxide layers onto titanium substrates for improved corrosion resistance and cytocompatibility," Surf. Coat. Technol., vol. 272, pp. 58-65, 2015. https://doi.org/10.1016/j.surfcoat.2015.04.024.

[26] E. Niemi, W. Serlo, E. Niemela, P. Sandvik, H. Pernu, and T. Salo, "Biocompatibility of nickel-titanium shape memory metal and its corrosion behavior in human cell cultures," pp. 4-6, 1996.

[27] K. Otsuka and X. Ren, "Physical metallurgy of Ti - Ni-based SMA's," vol. 50, pp. 511-678, 2005.

[28] S. K. Wu, Y. S. Chen, and J. Z. Chen, "Composition control of r. f. -sputtered Ti $50 \mathrm{Ni} 40 \mathrm{Cu} 10$ thin ${ }^{\circ} \mathrm{lms}$ using optical emission spectroscopy," vol. 365, 2000.

[29] S. N. Saud, E. Hamzah, and T. Abubakar, "Microstructure and corrosion behaviour of $\mathrm{Cu}-\mathrm{Al}$ - Ni SMA's with Ag nanoparticles," no. Xxx, pp. 1-8, 2014.

[30] M. Alizadeh and M. K. Dashtestaninejad, "Fabrication of manganese-aluminum bronze as a SMA by accumulative roll bonding process," JMADE, vol. 111, pp. 263-270, 2016. https://doi.org/10.1016/j.matdes.2016.08.074.

[31] H. Temperature, S. Memory, and A. Problems, "Journal of Intelligent Material Systems and Structures," 2012.

[32] U. Sar and T. K, "Effects of deformation on microstructure and mechanical properties of a $\mathrm{Cu}$ - Al - Ni SMA," vol. 59, 2007.

[33] L. G. Ć, E. Požega, A. Kostov, N. V. Ć, V. K. Ć, D. Ž. Ć, and L. B. C, "Thermodynamics and characterization of shape memory $\mathrm{Cu}-$ Al - Zn alloys," vol. 25, pp. 2630-2636, 2015

[34] J. Liu, H. Huang, and J. Xie, "Superelastic anisotropy characteristics of columnar-grained $\mathrm{Cu}-\mathrm{Al}-\mathrm{Mn}$ SMA's and its potential applications," JMADE, vol. 85, pp. 211-220, 2015 https://doi.org/10.1016/j.matdes.2015.06.114.

[35] R. Dasgupta, A. K. Jain, P. Kumar, S. Hussain, and A. Pandey, "Role of alloying additions on the properties of Cu-Al-Mn SMA's," J. Alloys Compd., 2014.

[36] X. Balandraud, N. Barrera, P. Biscari, M. Gr, and G. Zanzotto, "Strain intermittency in shape-memory alloys," vol. 174111, pp. 1$11,2015$.

[37] J. Fornell, N. Tuncer, and C. A. Schuh, "Orientation dependence in superelastic Cu-Al-Mn-Ni micropillars," J. Alloys Compd., vol. 693, pp. 1205-1213, 2017. https://doi.org/10.1016/j.jallcom.2016.10.090.

[38] E. M. Mazzer, C. S. Kiminami, C. Bolfarini, R. D. Cava, W. J. Botta, and P. Gargarella, "Thermochimica Acta Thermodynamic analysis of the effect of annealing on the thermal stability of a $\mathrm{Cu}-\mathrm{Al}$ Ni - Mn SMA," Thermochim. Acta, vol. 608, pp. 1-6, 2015. https://doi.org/10.1016/j.tca.2015.03.024.

[39] S. N. Saud, E. Hamzah, and T. Abubakar, "Correlation of microstructural and corrosion characteristics of quaternary SMA's $\mathrm{Cu}$ í Al í Ni í X (X = Mn or Ti)," Trans. Nonferrous Met. Soc. China, vol. 25 , no. 4, pp. 1158-1170, 2015. https://doi.org/10.1016/S10036326(15)63711-6.

[40] S. Yang, F. Zhang, J. Wu, Y. Lu, Z. Shi, C. Wang, and X. Liu, "Superelasticity and shape memory effect in $\mathrm{Cu}-\mathrm{Al}-\mathrm{Mn}-\mathrm{V}$ SMA's," JMADE, vol. 115, pp. 17-25, 2017. https://doi.org/10.1016/j.matdes.2016.11.035.

[41] K. Kanayo, E. Anita, and N. Maledi, "Phase characterisation and mechanical behaviour of $\mathrm{Fe}-\mathrm{B}$ modified $\mathrm{Cu}-\mathrm{Zn}-\mathrm{Al}$ SMA's," Integr. Med. Res., no. x x, pp. 1-11, 2017.

[42] M. Shahverdi, C. Czaderski, and M. Motavalli, "Iron-based SMA's for prestressed near-surface mounted strengthening of reinforced concrete beams," Constr. Build. Mater. vol. 112, pp. 28-38, 2016. https://doi.org/10.1016/j.conbuildmat.2016.02.174.

[43] H. Ozcan, J. Ma, S. J. Wang, I. Karaman, Y. Chumlyakov, J. Brown, and R. D. Noebe, "Scripta Materialia Effects of cyclic heat treatment and aging on superelasticity in oligocrystalline Fe-MnAl-Ni SMA wires," vol. 134, pp. 66-70, 2017.

[44] C. Czaderski, M. Shahverdi, R. Brönnimann, C. Leinenbach, and M. Motavalli, "Feasibility of iron-based SMA strips for prestressed strengthening of concrete structures," Constr. Build. Mater. vol. 56, pp. 94-105
[45] W. J. Lee, B. Weber, and C. Leinenbach, "Recovery stress formation in a restrained $\mathrm{Fe}-\mathrm{Mn}-\mathrm{Si}$-based SMA used for prestressing or mechanical joining," Constr. Build. Mater. vol. 95, pp. 600610, 2015. https://doi.org/10.1016/j.conbuildmat.2015.07.098.

[46] A. Ojha and H. Sehitoglu, "Transformation Stress Modeling in New Fe-Mn-Al-Ni SMA," Int. J. Plast., 2016. https://doi.org/10.1016/j.ijplas.2016.08.003

[47] G. Tadayyon, M. Mazinani, Y. Guo, and S. Mojtaba, "Materials Characterization Study of the microstructure evolution of heat treated Ti-rich NiTi SMA," Mater. Charact. vol. 112, pp. 11-19, 2016. https://doi.org/10.1016/j.matchar.2015.11.017.

[48] C. Van Der Eijk, Z. K. Sallom, and O. M. Akselsen, "Microwave brazing of NiTi SMA with $\mathrm{Ag}-\mathrm{Ti}$ and $\mathrm{Ag}-\mathrm{Cu}-\mathrm{Ti}$ alloys," vol. 58, pp. 779-781, 2008

[49] R. H. Shiue and S. K. Wu, "Infrared brazing of Ti 50 Ni 50 SMA using two $\mathrm{Ag}-\mathrm{Cu}-\mathrm{Ti}$ active braze alloys," vol. 14, pp. 630-638, 2006.

[50] J. P. Oliveira, F. M. B. Fernandes, N. Schell, and R. M. Miranda, "Shape memory effect of laser welded NiTi plates," vol. 8, no. 6, pp. 1-5, 2015.

[51] J. Bhagyaraj, K. V Ramaiah, C. N. Saikrishna, and S. K. Bhaumik, "Behaviour and effect of Ti 2 Ni phase during processing of NiTi SMA wire from cast ingot," J. Alloys Compd., 2013. https://doi.org/10.1016/j.jallcom.2013.07.046.

[52] H. Li, D. Sun, X. Gu, P. Dong, and Z. Lv, "Effects of the thickness of $\mathrm{Cu}$ filler metal on the microstructure and properties of laserwelded TiNi alloy and stainless steel joint," Mater. Des. vol. 50, pp 342-350, 2013. https://doi.org/10.1016/i.matdes.2013.03.014

[53] H. X. Zheng, J. Mentz, M. Bram, H. P. Buchkremer, and D. St, "Powder metallurgical production of TiNiNb and TiNiCu SMA's by combination of pre-alloyed and elemental powders," vol. 463, pp. 250-256, 2008.

[54] Z. G. Wei, S. Miyazaki, W. Tang, and R. Sandstro, "Experimental Investigation and Thermodynamic Calculation of the Ti-Ni-Cu SMA's," vol. 31, no. October, pp. 2423-2430, 2000.

[55] L. Duesseldorf, "No Title," vol. 395, pp. 161-164, 2002.

[56] Y. Zhou, M. Li, Y. Cheng, Y. F. Zheng, T. F. Xi, and S. C. Wei, "Surface \& Coatings Technology Tantalum coated NiTi alloy by PIIID for biomedical application," vol. 228, no. 5, pp. 2-6, 2013.

[57] M. Manjaiah, S. Narendranath, and S. Basavarajappa, "Review on non-conventional machining of SMA's," Trans. Nonferrous Met. Soc. China, vol. 24, no. 1, pp. 12-21, 2014. https://doi.org/10.1016/S1003-6326(14)63022-3.

[58] D. J. Hartl and D. C. Lagoudas, "Aerospace applications of SMA's," vol. 221, pp. 535-552, 2007.

[59] I. Physics, "Micro/miniature SMA actuator," pp. 2156-2161, 1990.

[60] H. Search, C. Journals, A. Contact, M. Iopscience, S. Mater, and I. P. Address, "A review on SMA's with applications to morphing aircraft," vol. 63001.

[61] R. Cortez-vega and I. Chairez, "A Hybrid Dynamic Model of SMA Spring Actuators A Hybrid Dynamic Model of SMA Spring Actuators," Measurement, 2017.

[62] A. Gessow, "An Improved SMA Actuator," vol. 14, no. December, 2003.

[63] C. B. Churchill, A. Arbor, and A. L. Browne, "SMA'SIS2011-," pp. $1-6,2016$.

[64] S. Vollach, R. Caciularu, and D. Shilo, "Scripta Materialia Equilibrium stress during the response of SMA's to an abrupt heat pulse," Scr. Mater., vol. 141, pp. 50-53, 2017. https://doi.org/10.1016/j.scriptamat.2017.07.016.

[65] M. R. Caskey, G. D. Embry, R. Maurice, and S. S. In-, "COUPLING TECHNOLOGY," no. April, 1979.

[66] D. Stoeckel, "“ S lm \#\# A I," vol. 11, no. 6, pp. 302-307, 1991.

[67] E. A. Williams, G. Shaw, and M. Elahinia, "Mechatronics Control of an automotive SMA mirror actuator," Mechatronics, vol. 20, no. 5, pp. 527-534, 2010 https://doi.org/10.1016/j.mechatronics.2010.04.002.

[68] B. M. Barnes, D. E. Brei, J. E. Luntz, K. Strom, A. L. Browne, and N. Johnson, "SMA Resetable Spring Lift for Pedestrian Protection," vol. 6930, no. 2008, pp. 1-13, 2015.

[69] M. E-class, "Long-Time Stability of Ni-Ti-SMA's for Automotive Safety Systems," vol. 20, no. July, pp. 506-510, 2011

[70] A. Bellini, M. Colli, and E. Dragoni, "Mechatronic Design of a SMA Actuator for Automotive Tumble Flaps : A Case Study," vol. 56, no. 7, pp. 2644-2656, 2009

[71] M. Leary, S. Huang, T. Ataalla, A. Baxter, and A. Subic, "Design of SMA actuators for direct power by an automotive battery," $J$. Mater., vol. 43, pp. 460-466, 2013. https://doi.org/10.1016/j.matdes.2012.07.002. https://doi.org/10.1016/j.conbuildmat.2014.01.069. 
[72] W. P. B. Bauer, "Concept of a start-up clutch with nickel-titanium SMA's," pp. 41-47, 2010.

[73] A. Suman, A. Fortini, and M. Merlin, “ATI 2015 - 70th Conference of the ATI Engineering Association A SMA-Based Morphing Axial Fan Blade : Functional Characterization and Perspectives," vol. 82 , pp. 273-279, 2015.

[74] A. J. Angilella, F. S. Gandhi, and T. F. Miller, "Design and testing of a SMA buoyancy engine for unmanned underwater vehicles," Smart Mater. Struct. vol. 24, no. 11, p. 115018. https://doi.org/10.1088/0964-1726/24/11/115018.

[75] W. Wang, H. Rodrigue, H. Kim, M. Han, and S. Ahn, "Soft composite hinge actuator and application to compliant robotic gripper,' Compos. Part B, vol. 98, pp. 397-405, 2016. https://doi.org/10.1016/j.compositesb.2016.05.030.

[76] N. Ma, G. Song, and H. Lee, "Position control of SMA actuators with internal electrical," vol. 777.

[77] H. Kim, M. Han, S. Song, and S. Ahn, "Soft morphing hand driven by SMA tendon wire," Compos. Part B, vol. 105, pp. 138-148, 2016. https://doi.org/10.1016/j.compositesb.2016.09.004.

[78] N. R. Fisco and H. Adeli, "Sharif University of Technology Smart structures : Part I - Active and semi-active control," Sci. Iran., vol. 18, no. 3, pp. 275-284, 2011 https://doi.org/10.1016/j.scient.2011.05.034.

[79] N. B. Morgan, "Medical SMA applications the market and its products," vol. 378, pp. 16-23, 2004

[80] S. A. Thompson, "An overview of nickel - titanium alloys used in dentistry," vol. 44, no. 0, pp. 297-310, 2000.

[81] H. Fischer, B. Vogel, and A. Welle, "Applications of SMA's in medical instruments," vol. 13, no. 4, pp. 248-253, 2004

[82] Z. X. Khoo, J. Ee, M. Teoh, Y. Liu, and C. K. Chua, "3D printing of smart materials : A review on recent progresses in 4D printing," vol. 2759, no. October, 2015

[83] T. Publications and F. U. Berlin, "No Title," vol. 328, pp. 17-22, 2000.

[84] C. Costa, M. Monteiro, B. Rangel, and F. J. L. Alves, "Industrial and natural waste transformed into raw material," vol. 231, pp. 247-256, 2017. 